\title{
Os Portais da Transparência: um estudo sobre as informações disponibilizadas pelos municípios do Corede Rio da Várzea, $\mathrm{RS}^{1}$
}

\author{
Tagiane Graciel Fiorentin Tres* \\ Evandra Maria Fugalli**
}

\begin{abstract}
Resumo
O objetivo deste estudo é avaliar se os municípios do Corede Rio da Várzea, RS atendem às determinações da Lei no 12.527/2011 e da Lei Complementar no 131/2009, que normatizam a publicação das informações governamentais. A pesquisa classifica-se como descritiva, de levantamento documental, com abordagem quanti-qualitativa. Conclui-se que os municípios analisados atendem à Lei Complementar no 131/2009. Apenas o item referente à "disponibilização das informações em tempo real" não está sendo cumprido pela administração de todos os municípios. Quanto ao atendimento da Lei no $12.527 / 2011,65 \%$ dos itens verificados obtiveram respostas positivas, evidenciando o comprometimento das administrações com a divulgação de informações públicas. Os municípios estudados não tiveram grandes avanços desde o estudo realizado pelo Tribunal de Contas do Estado do Rio Grande do Sul em 2013.
\end{abstract}

Palavras-chave: Transparência. Contas Públicas. Lei nº 12.527/2011. Lei Complementar no $131 / 2009$.

* Graduada em Ciências Contábeis pela Universidade de Passo Fundo. Especialista em Contabilidade Pública pela Universidade Regional do Noroeste do Estado do Rio Grande do Sul. Especialista em Controladoria e Gestão Tributária pela Universidade de Passo Fundo. Mestranda em Educação na Universidade de Passo Fundo. Professora na Universidade de Passo Fundo. E-mail: tfiorentin@upf.br

** Graduada em Ciências Contábeis pela Universidade de Passo Fundo. E-mail: evandra.fugalli@ gmail.com

http://dx.doi.org/10.5335/rtee.v22i47.6832

Submissão: 14/06/2015. Aceite: 23/09/2016. 


\section{Introdução}

A transparência é considerada um princípio da gestão fiscal responsável, ligada diretamente ao princípio constitucional da publicidade. Ela estimula a divulgação das ações dos agentes públicos e visa garantir o acesso às informações relativas à arrecadação e aplicação dos recursos públicos, servindo ao cidadão como instrumento de controle social e ao gestor como mecanismo de punição em caso de não atendimento.

O processo de regulamentação do princípio constitucional da publicidade ganhou força com a Lei Complementar n⿳o 101/2000, denominada Lei de Responsabilidade Fiscal (LRF), que está assentada nos pilares norteadores do planejamento, da responsabilização, do controle e da transparência. Na mesma esteira, foi editada a Lei Complementar nº 131/2009, conhecida como Lei da Transparência. Seu objetivo principal é regulamentar a Lei Complementar n⿳丷ㅜ 101/2000 no que tange à transparência e à publicidade das contas públicas. A determinação foi no sentido de que os governos disponibilizassem, em tempo real, as informações sobre as receitas e despesas, em meio eletrônico, possibilitando o acesso público e propiciando ao cidadão informações de forma simples e compreensível.

Na sequência, a Lei no 12.527/2011, a Lei de Acesso à Informação (LAI), foi promulgada, garantindo o acesso às informações governamentais que devem ser executadas de acordo com os princípios básicos da administração pública, enfatizando a publicidade. Os principais pontos evidenciados na LAI que os meios eletrônicos devem apresentar são: a estrutura organizacional, os endereços e números de telefone, os programas e ações, o orçamento e a despesa, as licitações e os contratos, os repasses ou transferência de recursos, entre outros detalhes. As informações disponibilizadas nos portais, segundo a lei, devem ser transparentes, claras e de fácil compreensão.

O meio eletrônico, portanto, constituiu-se como o principal canal de divulgação das informações referidas pela legislação, e são denominados Portais da Transparência. A obrigatoriedade de divulgar nos meios eletrônicos as informações sobre a gestão pública traz clareza aos atos públicos e fortalece a democracia brasileira. Com mais transparência na coisa pública, os atos de corrupção e má gestão tendem a se reduzir, aumentando a governança da administração e fazendo com que os gestores planejem suas ações.

Tendo em vista a grande quantidade de informações que devem ser publicadas e o prazo para o atendimento das referidas leis, este estudo objetiva avaliar se os municípios que fazem parte do Conselho Regional de Desenvolvimento (Corede) Rio da Várzea, Rio Grande do Sul, atendem às determinações legais sobre a publicação das informações governamentais. 


\section{Referencial teórico}

Nesta seção são apresentadas as principais referências que fundamentaram o presente estudo.

\subsection{A contabilidade pública como instrumento de controle social}

Nas últimas décadas, especialmente após a promulgação da Constituição federal de 1988 (CF/1988), o cidadão brasileiro passou a desempenhar o papel de protagonista na gestão pública, contribuindo com sugestões, fiscalizando e controlando os atos dos gestores e a contabilidade apresenta-se como uma ferramenta para o exercício dessa democracia. A função social da contabilidade consiste em instrumentalizar o cidadão para o controle social, conforme consta na Norma Brasileira de Contabilidade Aplicada ao Setor Público no 16.1. Trata-se de um compromisso fundado na ética profissional, que pressupõe o exercício cotidiano de fornecer informações que sejam compreensíveis e úteis aos cidadãos no desempenho de sua soberana atividade de controle do uso dos recursos e do patrimônio público pelos agentes públicos.

Todo o processo de evidenciação dos atos e fatos correlatos à administração pública inicia-se com a elaboração dos instrumentos de planejamento definidos na $\mathrm{CF}$ 1988. "O planejamento como instrumento de administração no setor público sempre foi amplamente debatido e exigido como requisito para a boa administração" (CAVALHEIRO, 2005, p. 26). Mas para que ocorra, de fato, o amplo debate, é indispensável que as "autoridades e a própria sociedade organizada estejam convencidas da necessidade da informação contábil como suporte para a tomada de decisões e mecanismos de controle na utilização dos recursos públicos" (PISCITELLI; TIMBÓ; ROSA, 1999, p. 29).

Com a consolidação da democracia brasileira, percebe-se que cada vez mais, a sociedade exige dos gestores públicos no planejamento e na execução das ações governamentais atitudes pautadas em princípios éticos e administrativos e em habilidades técnicas e políticas no trato com a coisa pública. Neiva argumenta que a "sociedade atual exige novo perfil da Administração Pública" em que o Estado, "ao invés de procurar impor sua vontade, deve propiciar fórmulas ou medidas que impliquem na participação dos integrantes da coletividade na elaboração de critérios para a realização de interesses coletivos” (NEIVA, 2011, p. 1). 
A contabilidade aplicada ao setor público está diretamente ligada à gestão de recursos públicos que alcançou, ao longo dos últimos anos, maior importância e valorização devido à utilidade das informações por ela geradas, pois ela utiliza uma técnica capaz de produzir, com oportunidade e fidedignidade, relatórios que sirvam no processo de tomada de decisões e controle de seus atos, demonstrando, por fim, os efeitos produzidos por esses atos de gestão no patrimônio da entidade (KOHAMA, 2012). A contabilidade pública é um mecanismo de controle dos atos e fatos relacionados ao patrimônio e ao orçamento público, representando uma ferramenta que proporciona ao gestor e à sociedade, informações necessárias para a tomada de decisões e o para o controle social, respectivamente.

No cenário atual, em que a participação da sociedade está ganhando espaço na gestão pública, também se coloca a contabilidade governamental em evidência na medida em que auxilia na tomada de decisões sobre a gestão dos recursos e proporciona aos usuários informações adequadas de interesse da coletividade, seja sobre a situação patrimonial e financeira da entidade, seja sobre o planejamento e execução do orçamento ou, ainda, sobre os custos de determinada obra ou serviço colocado à disposição da sociedade, como também sobre atos potencias que poderão vir a alterar a situação da entidade no futuro.

\subsection{A transparência pública no Brasil: a influência da Lei Complementar no $131 / 2009$ e da Lei 12.527/2011}

Os detentores do poder têm o "dever administrativo de manter plena transparência em seus comportamentos. Não poderá haver em um Estado Democrático de Direito, no qual o poder reside no povo, ocultamento aos administrados dos assuntos que a todos interessam" (MELLO, 2011, p. 114).

Silva defende que "a noção de transparência no âmbito governamental é cada vez mais empregada em países que defendem o processo democrático de acesso às informações sobre a ação dos gestores públicos” (2011, p. 350). O termo transparência na administração pública é amplamente utilizado para "designar o velho princípio da publicidade e afastar a atuação sigilosa” (DI PIETRO, 2011, p. 1),

O Instituto de Estudos Socioeconômicos (Inesc) define transparência pública como "indispensável à democracia, pois viabiliza o monitoramento entre os Poderes, portanto, o devido equilíbrio entre eles, aferindo assim o quanto eles estão sendo exercidos em prol dos legítimos interesses da sociedade" (2011, p. 3).

Uma boa gestão fiscal pressupõe responsabilidade e transparência. A gestão fiscal é transparente quando os "atos praticados pelo gestor público são divulgados 
amplamente de forma clara e objetiva à sociedade toda" (SILVA; AMORIM; SILVA, 2004, p. 115). Trata-se de introduzir na gestão pública a cultura da divulgação, da publicidade, da transparência, em que "a administração [...], sabendo que da boa comunicação interna e externa, particularmente quando espontânea, franca e rápida, resulta um clima de confiança, tanto internamente, quanto nas relações da empresa com terceiros" (SLOMSKI, 2009, p. 132).

A publicidade não se dá tão somente sob o aspecto da divulgação dos atos administrativos, mas, sim, da divulgação de forma clara e eficaz, ou seja, compreensível a toda população. Na visão de Speck, "a apresentação clara e transparente dos objetivos, dos recursos aplicados e de outras informações necessárias para a compreensão dos processos decisórios é fundamental para que a sociedade possa cobrar resultados e criticar omissões de seus governantes e representantes políticos" (2002, p.171), ou seja, "a administração transparente e democrática deve mostrar o que vai fazer e onde vai tirar os seus recursos, para que possa contar com a confiança da população, que pagará os seus tributos de uma maneira mais consciente e motivada" (KHAIR, 2001, p. 85).

"A transparência, como princípio da gestão fiscal responsável, pressupõe a publicidade e a compreensibilidade das informações" (PLATT NETO et al., 2007, p. 3). A compreensão das informações disponíveis pelos entes públicos deve permitir que qualquer cidadão usuário consiga identificar e entender onde e como o dinheiro público está sendo gasto. Somente dessa forma tem-se a efetiva participação da sociedade na gestão pública, realizando seu papel de controle social, necessário para atingir níveis satisfatórios na administração pública.

A divulgação das informações públicas geram benefícios à população. Justen Filho destaca que a "possibilidade de conhecimento público sobre as escolhas desincentiva a prática de irregularidades, especialmente em vista da ampliação da possibilidade de repressão a ilícitos e a desvios" (2008, p. 76). Além disso, os instrumentos de transparência, embora relativamente novos, "configuram-se como importantes elementos no processo democrático e participativo da população para a consolidação das políticas regionalizadas, estreitando as relações entre os interessados" (CASTOLDI; SANTOS, 2013, p. 170).

A transparência das contas governamentais favorece o exercício do controle social fornecendo elementos necessários ao cidadão, empoderando-o. Platt Neto et al., (2007) sustenta que a participação popular é alicerce do controle social e depende fortemente da transparência das ações governamentais e das contas públicas, pois sem informações as decisões são prejudicadas. Nesse sentido, transparência é um conceito mais amplo do que publicidade, isso porque uma informação pode ser pública, mas não ser relevante, confiável, tempestiva e compreensível. 
A LRF foi muito importante no fortalecimento do princípio da publicidade, mas foi a Lei Complementar n¹31/2009 que consolidou a transparência das contas públicas. Ela acrescentou dispositivos à LRF a fim de determinar a disponibilização, em tempo real, de informações pormenorizadas sobre a execução orçamentária e financeira da União, dos Estados, do Distrito Federal e dos municípios.

A referida lei, no entendimento de Martins, Coelho e Almeida (2012) institui a obrigatoriedade de se fazer transparente todas as informações públicas, por intermédio de um portal eletrônico, pois facilita a execução de uma efetiva fiscalização e controle, se houver a disponibilização de informações em tempo real. Esse regramento é utilizado para auxiliar a sociedade no seu papel de fiscalizador, uma vez que essa lei determina a divulgação de informações referentes aos lançamentos e recebimentos de todas as receitas, e quanto às despesas, os entes devem disponibilizar, no mínimo, dados referentes ao número do processo, ao bem fornecido ou ao serviço prestado, à pessoa física ou jurídica beneficiária do pagamento e, quando for o caso, ao procedimento licitatório realizado.

Em linhas gerais, a Lei Complementar nº 131/2009 determinou aos entes públicos, a disponibilização em tempo real, de informações sobre a execução orçamentária e financeira. A Controladoria Geral da União (CGU) (CONTROLADORIA GERAL DA UNIÃO, 2013a, p. 26), buscando orientar os municípios sobre a implementação da referida lei, definiu o termo "tempo real" como a divulgação das informações para acesso público, em meio eletrônico até o primeiro dia útil subsequente à data do registro contábil no respectivo sistema, sem prejuízo do desempenho e da preservação das rotinas de segurança operacional necessários ao seu pleno funcionamento.

A lei prevê que os entes que não disponibilizarem as informações no prazo estabelecido sofrerão penalidades. O impedimento de receber transferências voluntárias é o que mais preocupa os gestores públicos, uma vez que as transferências voluntárias representam uma importante fonte de receita necessária para a realização de investimentos públicos.

Vieira e França afirmam que o país necessita de "administradores que cumpram as disposições legais e permitam que qualquer pessoa saiba onde, quanto e como o dinheiro público está sendo arrecadado e gasto" (2011, p. 16).

Os sítios de internet são ferramentas utilizadas para garantir a boa e correta aplicação dos recursos públicos. O Portal da Transparência "é um canal onde os cidadãos podem acompanhar diretamente os gastos realizados pelos poderes Executivo, Legislativo e Judiciário, além do Tribunal de Contas do Estado e o Ministério Público" (MARTINS; COELHO; ALMEIDA, 2012, p. 5) e devem facilitar o acesso às informações seguindo as normas internacionais de desenvolvimento "a observância a esses critérios tem por objetivo possibilitar uma navegação mais 
fácil e inclusa para o cidadão que utilizar as ferramentas oferecidas pelo portal" (CONTROLADORIA GERAL DA UNIÃO, 2013a, p. 7).

As principais informações que devem ser disponibilizadas, de acordo com o determinado pelas Lei Complementar n⿳0 131/2009, são aquelas relativas à execução orçamentária e financeira, ou seja, a "arrecadação da receita e à execução da despesa fixada na Lei Orçamentária Anual” (VIEIRA; FRANÇA, 2011, p. 6). Quanto à despesa, devem ser publicados todos os atos praticados pelas unidades gestoras no decorrer da execução da despesa, no momento de sua realização (CONTROLADORIA GERAL DA UNIÃO, 2013a, p. 25), ou seja, as despesas deverão pelo menos ter as seguintes informações: o valor do empenho, liquidação e pagamento, classificação orçamentária com unidade orçamentária, função, subfunção, natureza da despesa, a fonte dos recursos que financiam o gasto, o número do processo da execução e a pessoa física ou jurídica beneficiada com o pagamento.

Quanto à receita, deve ser publicado o lançamento e o recebimento de toda a receita das unidades gestoras (CONTROLADORIA GERAL DA UNIÃO, 2013a, p. 25), com os valores de todas as receitas da unidade gestora e sua natureza, relativos à previsão, ao lançamento, à arrecadação, inclusive aos recursos extraordinários.

A gestão financeira, por sua vez, refere-se ao fluxo de recebimentos e pagamentos constantes da programação financeira do ente que "devem ser registradas no sistema no momento da ocorrência de seu fato gerador, independentemente de seu pagamento ou recebimento" (VIEIRA; FRANÇA, 2011, p. 6), evidenciando o princípio contábil da competência.

Entretanto, segundo Vieira (2011) cumprir essas determinações é um problema para a maioria dos entes da federação, pois a Lei da Transparência promoveu a abertura de uma caixa-preta que até então era protegida pela maioria dos cofres públicos. Conforme pesquisa realizada pelo Instituto de Estudos Socioeconômicos em março de 2011, mais de 70\% das capitais do país disponibilizam suas informações orçamentárias e financeiras em seus Portais de Transparência de forma péssima, ruim ou medíocre (INSTITUTO DE ESTUDOS SOCIOECONÔMICOS, 2011).

Um bom sistema de informática é fundamental no processo de implementação das exigências da Lei Complementar no 131/2009. Espera-se que o suporte possibilite o armazenamento, a importação e exportação dos dados disponíveis, além de possuir mecanismos que garantam a integridade e confiabilidade das informações. A lei criou critérios que os entes públicos devem atender quanto à qualidade mínima das informações.

Os agentes públicos que não respeitarem a Lei Complementar nº 131/2009, suas exigências e regulamentação, de acordo com Vieira e França "poderão sofrer ações de improbidade administrativa por atentarem contra o princípio da 
publicidade" (2011, p. 5). As sanções variam da perda da função pública, suspensão dos direitos políticos de três a cinco anos e multa.

Os entes sujeitos à LRF igualmente tiveram de se adequar à Lei Complementar no 131/2009, criando os Portais da Transparência e obedecendo a determinados prazos. A lei estabeleceu prazo de adequação até 28 de maio de 2010, para a União, os Estados, o Distrito Federal e os municípios com mais de 100 mil habitantes. Para os municípios com população entre 100 mil e 50 mil habitantes, o prazo findou em 28 de maio de 2011; para os municípios com até 50 mil habitantes o prazo estabelecido pela lei foi 28 de maio de 2013.

Recentemente, a Lei no 12.527/2011, denominada Lei de Acesso à Informação, foi editada com o objetivo de regular o acesso às informações, previsto no inciso XXXIII do artigo $5^{\mathrm{o}}$, no inciso II do $\S 3^{\circ}$ do artigo 37 e no $\S 2^{\circ}$ do $\operatorname{artigo} 216$ da $\mathrm{CF} / 1988$, ou seja, garantir ao cidadão o acesso amplo a qualquer documento ou informação de interesse público.

A CF/1988 refere-se a tal assunto, sustentando que todos têm direito de receber dos órgãos públicos informações de interesse particular ou coletivo. $\mathrm{O}$ acesso aos atos dos agentes públicos deve ser possibilitado a todos, cabendo à administração pública fornecer os meios para que isso ocorra.

O cumprimento da LAI refere-se a todos os órgãos públicos da administração direta, dos poderes Executivo e Legislativo, dos Tribunais de Contas, do Judiciário e do Ministério Público, além das autarquias, fundações e entidades sem fins lucrativos que recebam recursos públicos. Vários fatores impulsionaram a criação da LAI, Miola (2013, p. 10) cita, para exemplificar, a crescente preocupação da sociedade no trato com a coisa pública, a sensibilização acerca da supremacia do interesse público sobre o privado, a percepção sobre a importância do controle social no combate à corrupção e os compromissos internacionais do país em relação ao tema.

A referida lei, em seu art. 5o, aponta que "é dever do Estado garantir o direito de acesso à informação, que será franqueada, mediante procedimentos objetivos e ágeis, de forma transparente, clara e em linguagem de fácil compreensão" (BRASIL, 2011). Assim, as informações divulgadas na internet ou em outros meios devem ser compreensíveis para o público leigo, ou seja, livre de siglas ou termos técnicos, pois isso pode inviabilizar sua compreensão.

Quando amplamente divulgadas de forma clara e compreensível, as informações das administrações públicas geram resultados positivos para a sociedade e para o aperfeiçoamento da gestão governamental, pois "a corrupção, a má gestão e a inoperância administrativa se valem de ambientes obscuros, que tendem a se reduzir, com a LAI", pois ela permite que se traga luz aos atos e fatos da 
administração. $\mathrm{O}$ acesso às informações públicas é um requisito importante para a luta contra a corrupção, o aperfeiçoamento da gestão pública, o controle social e a participação popular (CONTROLADORIA GERAL DA UNIÃO, 2013b, p. 6).

O grande mérito da LAI, segundo Miola (2013), está em oportunizar que se traga para o mundo dos fatos o que antes era uma previsão abstrata, mesmo contida na $\mathrm{CF} / 1988$. A criação da nova lei vai muito além de simplesmente fixar regras procedimentais, institucionalizou a transparência como uma diretriz de gestão, trouxe um amadurecimento para a democracia brasileira, que, com esse mecanismo de ampla acessibilidade, poderá avançar ainda mais. Acredita-se também que a LAI promoveu uma grande mudança cultural tanto nas administrações como na sociedade ao franquear a informação a todos, representando um importante passo na construção de uma sociedade livre, justa e solidária (MIOLA, 2013, p. 12).

No ano de 2012, a Câmara dos Deputados Federais elaborou uma Cartilha de Orientações ao Cidadão, mencionando que a referida lei regulamenta o direito à informação garantida pela Constituição federal, obrigando os órgãos públicos a considerar a publicidade como regra e o sigilo como exceção e salienta que os objetivos da lei são fomentar o desenvolvimento de uma cultura de transparência e controle social na administração pública.

De acordo com o apresentado no artigo $8^{\circ}$ da LAI, algumas informações mínimas devem ser disponibilizadas nos portais, como estrutura administrativa, registros das despesas e repasses de recursos financeiros, procedimentos licitatórios, editais, contratos, dados sobre programas, ações, projetos e obras, respostas e perguntas. No entanto, os órgãos públicos podem e devem definir outras informações que possam ter interesse coletivo e merecem divulgação.

A LAI estabelece também que os órgãos públicos disponibilizem o Serviço de Informação ao Cidadão (SIC), necessário ao processo de atendimento ao público, que serve para envio de pedidos de informações. Cada ente federativo pode regulamentar seu SIC, que deve possibilitar o registro de pedidos de informação e o acompanhamento dos trâmites e prazos, a realização de reclamações, de consultas a respostas recebidas, a protocolos de documentos e requerimentos, entre outros serviços. Os SICs podem ser criados nos portais da internet ou em espaços físicos nos órgãos públicos, já que ainda muitas pessoas não têm ferramentas ou computadores com acesso à internet.

Outro ponto importante que a LAI destaca é o fornecimento de informações de forma gratuita, salvo quando houver cópias de documentos, quando poderá ser cobrado o ressarcimento do valor dos custos dos serviços e materiais utilizados. Também não serão permitidas divulgações classificadas como sigilosas pelas 
autoridades competentes, ou seja, quando consideradas imprescindíveis à segurança da sociedade ou do Estado, como descrito no artigo 23 da LAI. Também, conforme 0 artigo 31, as informações pessoais, relativas à intimidade, privacidade, honra e imagem, que não dizem respeito ao interesse público, devem ser preservadas por prazo de cem anos, a contar da data de sua produção, com exceção quando forem apurados casos de irregularidade.

Os portais precisam ser elaborados de forma a facilitar o acesso dos cidadãos, com ferramentas de busca, garantindo que as informações possam ser utilizadas amplamente. Contudo, em plena era da informação, algumas prefeituras não têm nem mesmo portais na internet e ainda mantêm as informações públicas em segredo, o mesmo acontece também com os Poderes Legislativos (INSTITUTO DE ESTUDOS SOCIOECONÔMICOS, 2011). É preciso conscientizar o agente público quanto à importância da transparência, já que a cultura de que o servidor é o dono da informação que produziu não tem mais lugar no ambiente que se pretende garantir o direito de acesso à informação.

A CGU refere-se que a "transparência e acesso à informação são termos que devem ser inseridos nas rotinas e procedimentos do serviço público" (2013b, p. 34), pois, se a administração é pública, públicas são as informações produzidas por ela, salvo algumas exceções previstas em lei. Para garantir a qualidade das informações e, consequentemente, a qualidade da LAI é necessário um constante acompanhamento das atividades de atendimento ao cidadão, capacitação de servidores, engajamento das autoridades e uma permanente atualização dos portais.

Os entes públicos que descumprirem a LAI estão sujeitos à improbidade administrativa, conforme disposto na Lei de Improbidade Administrativa no 8.429/1992.

A legislação obriga todos os órgãos públicos brasileiros ao cumprimento da Lei Complementar n⿳10131/2009, que trata da divulgação das informações sobre a execução orçamentária e financeira, e obriga apenas os municípios com mais de $10 \mathrm{mil}$ habitantes ao atendimento da Lei $\mathrm{n}^{\mathrm{0}}$ 12.527/2011, estimula aqueles que têm menos de 10 mil a adotar as providencias necessárias para a adequação à lei.

\section{Metodologia}

Esta pesquisa tem abordagem quanti-qualitativa, delineada para um estudo de natureza bibliográfica e documental em páginas de sítios web. Gil diz que "a internet constitui hoje um dos mais importantes veículos de informações” (2010, p. 57). Os sítios da web no entendimento de Diehl e Tatim (2004, p. 75) auxiliam na realização de pesquisas para coleta de dados por meio da qual o pesquisador 
pode ter acesso a uma grande quantidade de informações, que poderão servir como referência ao estudo. Ainda, os dispositivos de busca permitem refinar a pesquisa para direcioná-la de forma mais precisa, evitando a obtenção de resultados muito amplos ou muito restritos.

O universo de pesquisa é constituído por vinte municípios que fazem parte do Corede Rio da Várzea, RS. Os municípios que fazem parte do Corede Rio da Várzea, conforme o Decreto Estadual no 47.543, de 8 de novembro de 2010, são: Barra Funda, Boa Vista das Missões, Cerro Grande, Chapada, Constantina, Engenho Velho, Jaboticaba, Lajeado do Bugre, Liberato Salzano, Nova Boa Vista, Novo Barreiro, Novo Xingu, Palmeira das Missões, Ronda Alta, Rondinha, Sagrada Família, São José das Missões, São Pedro das Missões, Sarandi e Três Palmeiras.

Os dados foram coletados dos sítios dos municípios em estudo no período de $1^{\text {o }}$ de maio a 18 de maio de 2014, seguindo checklist elaborado pelas autoras, adaptado do estudo realizado pelo Tribunal de Contas do Estado do Rio Grande do Sul em 2013, que foi dividido em três blocos: a) atendimento à Lei Complementar $\mathrm{n}^{\mathrm{o}}$ 131/2009; b) atendimento à Lei $\mathrm{n}^{\mathrm{o}}$ 12.527/2011; c) qualidade das informações disponibilizadas.

Para avaliação das respostas do checklist da Lei Complementar no 131/2009, foram adotados os seguintes critérios: SIM, para quesitos atendidos, NÃO, para quesitos não atendidos, e ERRO, nos casos em que, embora os municípios dispusessem de portal próprio, não tenha sido possível acessar a página.

Para avaliação das respostas do checklist da Lei no 12.527/2012 e da qualidade das informações disponibilizadas adotaram-se os seguintes critérios: SIM, para quesitos atendidos, NÃO, para quesitos não atendidos, PARCIAL, para os quesitos cujos parâmetros não tenham sido atendidos em sua totalidade, e NÃO DISPONÍVEL (ND), para links inexistentes ou, caso tivessem sido encontrados, cujas informações não estavam disponíveis.

Conforme Beuren (2003), checklist é o instrumento de coleta de dados em que o pesquisador elabora um roteiro de itens que devem ser verificados e por meio de uma entrevista ou visita à amostra selecionada para pesquisa checa todos os elementos necessários para a aplicação de seu estudo monográfico.

\section{Análise de dados}

Nesta seção constam os dados relacionados ao Corede Rio da Várzea, à análise da Lei Complementar n⿳0131/2009, à análise da Lei ํㅜㄹ 12.527/2011 e à análise da qualidade das informações disponibilizadas nos sítios municipais. 


\subsection{Análise da Lei Complementar nº 131/2009}

O Quadro 1 apresenta as questões e respectivas respostas do estudo sobre e Lei Complementar no 131/2009.

Quadro 1 - Análise da Lei Complementar $n^{\circ}$ 131/2009

\begin{tabular}{|c|c|c|c|c|c|c|c|c|c|}
\hline 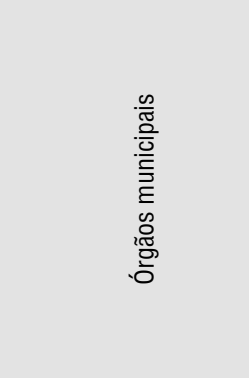 & 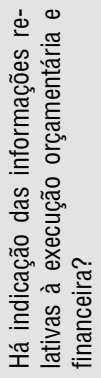 & 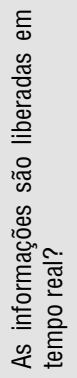 & 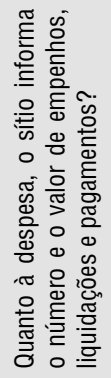 & 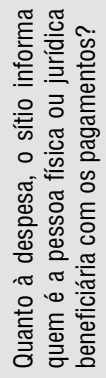 & 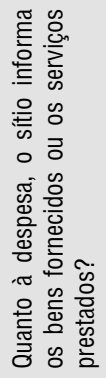 & 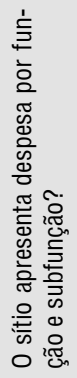 & 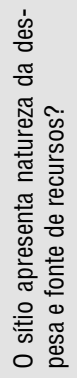 & 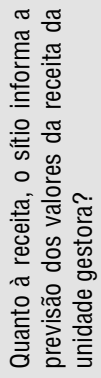 & 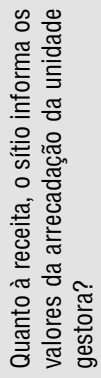 \\
\hline Barra Funda & SIM & SIM & SIM & SIM & SIM & SIM & SIM & SIM & SIM \\
\hline Boa Vista das Missões & SIM & NÃO & SIM & SIM & SIM & SIM & SIM & SIM & SIM \\
\hline Cerro Grande & SIM & NÃO & SIM & SIM & SIM & SIM & SIM & SIM & SIM \\
\hline Chapada & SIM & NÃO & SIM & SIM & SIM & SIM & SIM & SIM & SIM \\
\hline Constantina & SIM & NÃO & SIM & SIM & SIM & SIM & SIM & SIM & SIM \\
\hline Engenho Velho & SIM & SIM & SIM & SIM & SIM & SIM & SIM & SIM & SIM \\
\hline Jaboticaba & SIM & NÃO & SIM & SIM & SIM & SIM & SIM & SIM & SIM \\
\hline Lajeado do Bugre & SIM & NÃO & SIM & SIM & SIM & SIM & SIM & SIM & SIM \\
\hline Liberato Salzano & SIM & NÃO & SIM & SIM & SIM & SIM & SIM & SIM & SIM \\
\hline Nova Boa Vista & SIM & SIM & SIM & SIM & SIM & SIM & SIM & SIM & SIM \\
\hline Novo Barreiro & SIM & SIM & SIM & SIM & SIM & SIM & SIM & SIM & SIM \\
\hline Novo Xingu & SIM & NÃO & SIM & SIM & SIM & SIM & SIM & SIM & SIM \\
\hline Palmeira das Missões & SIM & SIM & SIM & SIM & SIM & SIM & SIM & SIM & SIM \\
\hline Ronda Alta & SIM & SIM & SIM & SIM & SIM & SIM & SIM & SIM & SIM \\
\hline Rondinha & SIM & SIM & SIM & SIM & SIM & SIM & SIM & SIM & SIM \\
\hline Sagrada Família & SIM & NÃO & SIM & SIM & SIM & SIM & SIM & SIM & SIM \\
\hline São José das Missões & SIM & NÃO & SIM & SIM & SIM & SIM & SIM & SIM & SIM \\
\hline São Pedro das Missões & SIM & NÃO & SIM & SIM & SIM & SIM & SIM & SIM & SIM \\
\hline Sarandi & SIM & SIM & SIM & SIM & SIM & SIM & SIM & SIM & SIM \\
\hline Três Palmeiras & SIM & NÃO & SIM & SIM & SIM & SIM & SIM & SIM & SIM \\
\hline
\end{tabular}

Fonte: elaborado pelas autoras, adaptado de Tribunal de Contas do Estado (2013).

A Lei Complementar n 131, publicada em 2009, obrigatória para a União, os Estados, o Distrito Federal e os municípios, independente do número de habitantes, amplia a transparência na gestão dos recursos públicos e incentiva o exercício do controle social. Ainda que para os municípios com população de até $50 \mathrm{mil}$ habitantes a lei tenha conferido prazo de quatro anos para implantação, esse prazo 
encerrou-se em maio de 2013, estando, portanto, em vigência em 2014. A análise do Quadro 1 permite inferir que a lei está sendo atendida pelos municípios em estudo quase que na totalidade, corroborando o estudo realizado pelo Tribunal de Contas do Estado do Rio Grande do Sul em 2013. Observou-se que 60\% dos municípios não atendem ao quesito "liberação das informações em tempo real", pois mesmo nos casos em que o sítio é atualizado diariamente, algumas informações não eram disponibilizadas no primeiro dia útil subsequente à data do registro.

\subsection{Análise da Lei no $12.527 / 2011$}

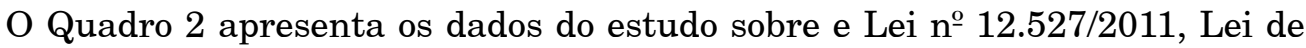
Acesso à Informação

Quadro 2 - Análise da Lei nº 12.527/2011

\begin{tabular}{|c|c|c|c|c|c|c|c|c|c|c|c|c|}
\hline 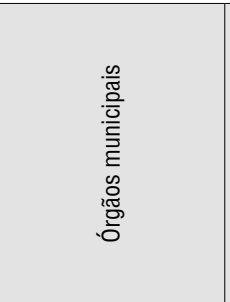 & 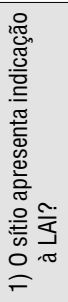 & 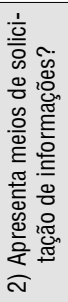 & 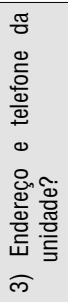 & 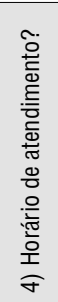 & 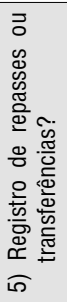 & 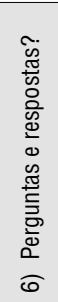 & 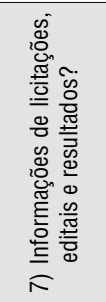 & 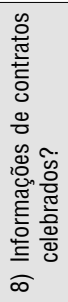 & 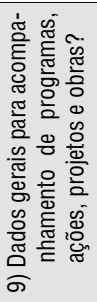 & 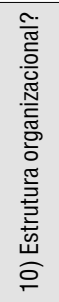 & 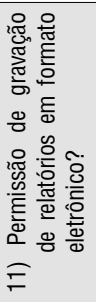 & 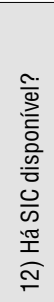 \\
\hline Barra Funda & NÃO & NÃO & SIM & NÃO & SIM & NÃO & SIM & SIM & NÃO & SIM & SIM & NÃO \\
\hline Boa Vista das Missões & SIM & SIM & SIM & NÃO & SIM & NÃO & PARCIAL & SIM & SIM & SIM & SIM & SIM \\
\hline Cerro Grande & NÃO & NÃO & SIM & NÃO & SIM & NÃO & PARCIAL & NÃO & SIM & SIM & SIM & NÃO \\
\hline Chapada & NÃO & NÃO & SIM & NÃO & SIM & NÃO & SIM & NÃO & SIM & SIM & SIM & NÃO \\
\hline Constantina & NÃO & NÃO & SIM & NÃO & SIM & NÃO & NÃO & SIM & SIM & SIM & SIM & NÃO \\
\hline Engenho Velho & NÃO & NÃO & SIM & NÃO & SIM & NÃO & PARCIAL & SIM & NÃO & SIM & SIM & NÃO \\
\hline Jaboticaba & NÃO & NÃO & SIM & NÃO & SIM & SIM & PARCIAL & NÃO & SIM & SIM & SIM & ND \\
\hline Lajeado do Bugre & NÃO & NÃO & SIM & SIM & SIM & NÃO & PARCIAL & NÃO & SIM & SIM & SIM & NÃO \\
\hline Liberato Salzano & SIM & SIM & SIM & SIM & SIM & NÃO & PARCIAL & NÃO & SIM & SIM & SIM & SIM \\
\hline Nova Boa Vista & NÃO & NÃO & SIM & NÃO & SIM & NÃO & PARCIAL & NÃO & SIM & SIM & SIM & NÃO \\
\hline Novo Barreiro & NÃO & NÃO & SIM & NÃO & SIM & NÃO & PARCIAL & NÃO & SIM & NÃO & SIM & NÃO \\
\hline Novo Xingu & NÃO & NÃO & SIM & SIM & SIM & NÃO & PARCIAL & NÃO & SIM & SIM & SIM & NÃO \\
\hline Palmeira das Missões & SIM & SIM & SIM & NÃO & SIM & NÃO & SIM & SIM & SIM & SIM & SIM & SIM \\
\hline Ronda Alta & SIM & SIM & SIM & SIM & SIM & NÃO & PARCIAL & SIM & SIM & SIM & SIM & SIM \\
\hline Rondinha & NÃO & NÃO & SIM & NÃO & SIM & NÃO & PARCIAL & NÃO & NÃO & NÃO & SIM & NÃO \\
\hline Sagrada Família & SIM & SIM & SIM & NÃO & SIM & SIM & SIM & NÃO & SIM & SIM & SIM & SIM \\
\hline São José das Missões & NÃO & NÃO & SIM & SIM & SIM & NÃO & PARCIAL & NÃO & SIM & SIM & SIM & NÃO \\
\hline São Pedro das Missões & SIM & SIM & SIM & NÃO & SIM & SIM & PARCIAL & NÃO & SIM & SIM & SIM & SIM \\
\hline Sarandi & SIM & SIM & SIM & SIM & SIM & ND & PARCIAL & NÃO & SIM & SIM & SIM & ND \\
\hline Três Palmeiras & SIM & SIM & SIM & NÃO & SIM & SIM & SIM & NÃO & SIM & SIM & SIM & SIM \\
\hline
\end{tabular}

Fonte: elaborado pelas autoras, adaptado de Tribunal de Contas do Estado (2013). 
Embora a Lei no 12.527/2011 dispense municípios com população de até 10 mil habitantes de publicar dados e documentos públicos em meios eletrônicos, os direitos constitucionais enaltecem essa conduta, garantindo ao cidadão acesso ao que é público. Dos municípios em estudo, 15\% apresentam população acima de 10 mil habitantes (Palmeira das Missões, Ronda Alta e Sarandi) ficando, portanto obrigados a cumprir a LAI. Os demais $85 \%$ apresentam população inferior a 10 mil habitantes e estão desobrigados do cumprimento da referida lei.

A análise do Quadro 2 possibilita concluir que até 2014, não houve a tão esperada mudança de cultura sobre a disponibilização das informações ao público, pois informações básicas, como horário de atendimento e estrutura organizacional ainda não podem ser acessadas pelo público. Apenas $40 \%$ dos municípios em estudo apresentam indicação clara à LAI em sua página inicial, que consiste basicamente em apresentar os principais objetivos e o número da lei que rege esse processo, Lei n⿳o 12.527/2011. Grande parte dos municípios, $60 \%$, não apresenta meios de solicitação de informações por meio de requerimentos eletrônicos ou a indicação de locais físicos para atendimento ao quesito. Qualquer pessoa pode fazer pedido de informações a órgãos públicos e, se a informação não puder ser prestada, é necessário apresentar uma justificativa.

Também há baixo percentual de atendimento ao item que se refere à apresentação de link sobre perguntas e respostas, o quesito aparece em apenas 25\% dos sítios analisados. Um município, embora disponibilizasse o link, não enviava para o quadro de perguntas e respostas. Observou-se também que $70 \%$ dos municípios atendem parcialmente ao item sobre a divulgação de licitações, editais e resultados, enquanto que somente $25 \%$ apresentam pleno atendimento à questão. Notou-se que as informações relativas a licitações são divulgadas parcialmente, pois não consta, por exemplo, os resultados ou os licitantes vencedores.

O mesmo ocorre com a divulgação dos contratos celebrados. Cerca de $70 \%$ dos municípios não os publicam no site do município. Em 2013, no estudo feito pelo Tribunal de Contas do Estado do Rio Grande do Sul, o resultado foi semelhante, sendo que do total de 497 municípios do Rio Grande do Sul, 335 (67\%) municípios não divulgavam seus contratos.

Verificou-se também, que nos portais dos entes examinados $55 \%$ não apresentam Serviço de Informações ao Cidadão. Por outro lado, observaram-se alguns resultados positivos: todos os municípios pertencentes ao Corede Rio da Várzea disponibilizam informações quanto a repasses ou transferências. No estudo do Tribunal de Contas em 2013, observou-se que 426 municípios do total de 497 também disponibilizavam informações relativas a repasses ou transferências, $85 \%$ divulgam as 
informações para acompanhamento das ações do governo, ou seja, os Executivos, por meio de matérias, disponibilizam informações de cunho social, do andamento de obras da administração pública e informativas; todos os portais estudados apresentam meios de gravação dos arquivos em formato eletrônico, atendendo às exigências legais, os sítios, também possibilitam, comandos como copiar e colar.

\subsection{Análise da qualidade dos sítios municipais}

O Quadro 3 apresenta os dados do estudo sobre a qualidade das informações disponibilizadas nos Portais da Transparência.

Quadro 3 - Qualidade das informações

\begin{tabular}{|c|c|c|c|c|c|c|c|c|c|}
\hline 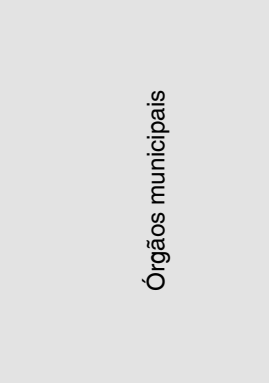 & 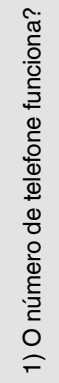 & 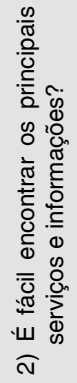 & 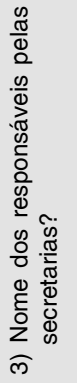 & 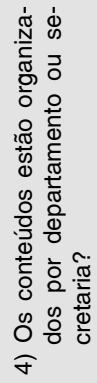 & 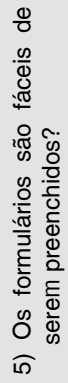 & 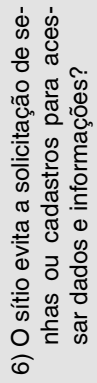 & 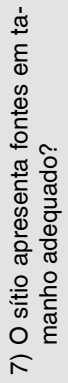 & 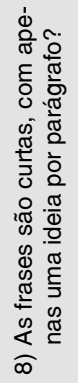 & 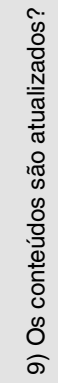 \\
\hline Barra Funda & SIM & SIM & SIM & NÃO & ND & SIM & SIM & SIM & ND \\
\hline Boa Vista das Missões & SIM & SIM & NÃO & SIM & SIM & SIM & SIM & SIM & SIM \\
\hline Cerro Grande & SIM & SIM & SIM & NÃO & ND & SIM & SIM & SIM & SIM \\
\hline Chapada & SIM & SIM & SIM & SIM & ND & SIM & SIM & SIM & SIM \\
\hline Constantina & SIM & SIM & SIM & NÃO & ND & SIM & SIM & SIM & SIM \\
\hline Engenho Velho & SIM & SIM & SIM & NÃO & ND & SIM & SIM & SIM & ND \\
\hline Jaboticaba & SIM & SIM & NÃO & NÃO & ND & SIM & SIM & SIM & SIM \\
\hline Lajeado do Bugre & SIM & SIM & NÃO & NÃO & ND & SIM & SIM & SIM & SIM \\
\hline Liberato Salzano & SIM & SIM & SIM & NÃO & SIM & SIM & SIM & SIM & SIM \\
\hline Nova Boa Vista & SIM & SIM & SIM & NÃO & ND & SIM & SIM & SIM & NÃO \\
\hline Novo Barreiro & SIM & SIM & NÃO & NÃO & ND & SIM & SIM & SIM & NÃO \\
\hline Novo Xingu & SIM & SIM & SIM & NÃO & ND & SIM & SIM & SIM & NÃO \\
\hline Palmeira das Missões & SIM & SIM & NÃO & SIM & SIM & SIM & SIM & SIM & SIM \\
\hline Ronda Alta & SIM & SIM & SIM & NÃO & SIM & SIM & SIM & SIM & SIM \\
\hline Rondinha & SIM & ND & ND & ND & ND & SIM & SIM & ND & ND \\
\hline Sagrada Família & SIM & SIM & SIM & NÃO & SIM & SIM & SIM & SIM & NÃO \\
\hline São José das Missões & SIM & SIM & SIM & SIM & ND & SIM & SIM & SIM & NÃO \\
\hline São Pedro das Missões & SIM & SIM & NÃO & NÃO & SIM & SIM & SIM & SIM & SIM \\
\hline Sarandi & SIM & SIM & SIM & NÃO & ND & SIM & SIM & SIM & SIM \\
\hline Três Palmeiras & SIM & SIM & SIM & NÃO & SIM & SIM & SIM & SIM & SIM \\
\hline
\end{tabular}

Fonte: elaborado pelas autoras. 
Os sítios governamentais foram criados para atender às necessidades do cidadão, que procura por informações. Quando se cria um sítio, deve-se levar em conta critérios como usabilidade, acessibilidade, veracidade da informação, agilidade do serviço e transparência.

A análise do Quadro 3 possibilita concluir que, em todos os municípios estudados, os telefones indicados nos sítios funcionam. Em 95\% dos municípios estudados, é fácil localizar os principais serviços e informações. Apenas $65 \%$ divulgam em meios eletrônicos os nomes dos responsáveis pelas suas secretarias. Os responsáveis pelos Executivos, quando nomeiam seus secretários, deveriam atentar a boas práticas de gestão pública e divulgarem para a comunidade a composição de suas secretarias.

Notou-se que, em $75 \%$ dos municípios em estudo, as informações e notícias vinculadas nos sítios estudados não estão organizadas por secretarias. Constatou-se ainda que $65 \%$ dos municípios não disponibilizam formulários para solicitação de informações, nos 35\% que disponibilizam formulários, os materiais são de fácil entendimento e preenchimento. Observou-se que todos os sítios dispensam a solicitação de senhas para obtenção de informações disponibilizadas. Levou-se em conta as informações disponibilizadas nos portais relacionadas às duas leis. Do exame, observou-se que $100 \%$ dos municípios disponibilizam fontes em tamanho adequado, que facilmente podem ser lidas, bem como as mantém em formato uniforme.

Neste trabalho também foi analisado se as informações ou notícias apresentavam fácil compreensão, com frases curtas e objetivas, imprescindíveis para a boa transparência, uma vez que todos os cidadãos, de qualquer classe social e escolaridade, têm o direito à informação e, portanto, os textos devem ser compreensíveis a todos. Não foram levadas em conta aqui as publicações oficiais, como editais de licitações ou concursos, que, por sua natureza, possuem linguagem técnica. Em 95\% dos municípios as frases de contextualização de notícias ou informações relacionadas à administração pública eram curtas e de fácil compreensão, compostas em linguagem clara e objetiva.

Quanto à atualização dos conteúdos, levou-se em conta se as notícias referentes às atividades dos Executivos estavam atualizadas, para essa análise considerou-se que pelos menos uma informação ou notícia estivesse atualizada no período de coleta os dados. Não foram levadas em consideração informações relacionadas a editais e licitações. Observou-se que os sítios apresentam conteúdos (notícia ou informação) atualizados em $60 \%$ dos municípios, contatou-se que três deles não apresentam link de notícias. 


\section{Considerações finais}

O presente estudo busca chamar a atenção para a ideia de um processo de transparência e divulgação das contas públicas cada vez mais necessárias em um país democrático. A implantação de programas de governo eletrônico vem ao encontro da democratização das informações públicas, aproximando o cidadão do governo. A Lei Complementar no 131/2009 e a Lei no⒈257/2012 surgiram como um poderoso instrumento de educação e cidadania fiscal, seus atos decorrem legalmente do processo de democracia do país, e não necessitariam de dispositivos constitucionais para sua aplicação.

A disponibilização das informações pelos órgãos públicos, nos meios eletrônicos, além de facilitar o acesso do cidadão, reduz os custos com a prestação de informações. A implantação dos portais municipais possibilitou o acesso à informação e a sociedade passou a ser protagonista das questões de interesse público. Os sítios devem permitir que o usuário faça uso de todas as ferramentas e sinta necessidade de retornar a fazer uso do serviço.

No presente estudo buscou-se analisar se os municípios que fazem parte do Corede Rio da Várzea estão atendendo às determinações da Lei Complementar $\mathrm{n}^{\circ}$ 131/2009 e da Lei no 12.527/2011 no que se refere à disponibilização das informações nos Portais da Transparência bem como a sua qualidade. Percebeu-se que, embora as informações encontradas nos sítios tivessem relevância, há necessidade de se melhorar o padrão de agilidade e rapidez de acesso.

No que se refere ao cumprimento da Lei Complementar no 131/2009, o estudo revelou que os municípios do Corede Rio da Várzea atendem quase que na totalidade à referida Lei, disponibilizando informações sobre a execução orçamentária e financeira. Ressalta-se que o não atendimento da lei ficou por conta da disponibilidade das informações em "tempo real”, já que $60 \%$ dos municípios não as disponibilizam no primeiro dia útil subsequente ao do fato gerador.

Quanto à Lei no 12.527/2011 e a qualidade dos sítios municipais, constatou-se que embora alguns municípios apresentem bons níveis em relação aos quesitos formulados, nenhum atendeu a todos. Ressalta-se que o descumprimento de alguns quesitos, como perguntas e respostas, horário de atendimento e contatos, foram observados em alguns sites dos municípios com mais de 10 mil habitantes. $O$ estudo mostrou que há boa adesão dos municípios do Corede Rio da Várzea em relação à

Lei no 12.527/2011, pois a grande maioria, por ter menos de 10 mil habitantes, está dispensada de divulgar informações na rede mundial de computadores. 
Quanto aos quesitos analisados, solicitados pela Lei 12.527/2011, e à qualidade dos sítios municipais, observou-se que $65 \%$ deles tiveram resposta afirmativa, ou seja, atenderam à referida lei, $26,19 \%$, resposta negativa, $5,48 \%$, tiveram registro de item não disponível e 3,33\%, atendimento parcial dos quesitos.

Cabe destacar o importante papel da contabilidade no cumprimento das leis sobre a transparência pública, especialmente da Lei Complementar n⿳ํㅡ 131/2009, pois todas as informações por ela exigidas são extraídas do sistema contábil e dos subsistemas de informações orçamentárias, financeiras, patrimonial, de custos e de compensação, e, portanto, necessitam estar devidamente integrados, de forma que as informações possam ser disponibilizadas de forma automática e tempestiva.

Como sugestão recomenda-se que os municípios que não cumprem o quesito “tempo real" da Lei Complementar nº131/2009, identifiquem as razões e solucionem o problema. Quanto ao que é tratado na Lei $\mathrm{n}^{\circ} 12.527 / 2011$, sugere-se que os municípios desobrigados ao cumprimento divulguem suas informações mesmo assim, pois como a informação é pública, deve ser levada ao conhecimento de todos. A criação de um software padrão poderia auxiliar na divulgação das informações e ser utilizado por qualquer município do Brasil.

Assim, nos dias atuais, do nosso estado democrático, é necessário que cada vez mais os gestores públicos divulguem informações, não somente as relacionadas à execução orçamentária e financeira, mas de todos os atos por eles realizados. 


\title{
The Portals of Transparency: a study on the information provided by the municipalities of Corede Rio da Várzea, RS
}

\begin{abstract}
The objective of this study is to assess whether the municipalities of COREDE Rio da Várzea/RS meet the provisions of Law No. 12.527/2011 and the Supplementary Law No.131/2009 on the publication of government information. The research is classified as descriptive, documental survey with quantitative and qualitative approach. We conclude that the municipalities analyzed meet the Supplementary Law No. 131/2009. Only the item referring to "availability of information in real time" is not being served by all municipalities. The service of Law No. 12.527/2011, 65\% of the checked items showed positive responses, showing the commitment of the authorities to the disclosure of public information. Municipalities studied did not achieve great advances since the study by the Tribunal de Contas do Estado do Rio Grande do Sul in 2013.
\end{abstract}

Keywords: Transparency. Public Accounts. Law No.12.527/2011. Complementary Law No. $131 / 2009$.

\section{Los Portales de la Transparencia: un estudio sobre la información proporcionada por los municipios del Corede Rio da Várzea, RS}

\section{Resumen}

El objetivo de este estudio es evaluar si los municipios del COREDE Rio da Várzea/RS cumplen las disposiciones de la Ley № 12.527/2011 y la Ley Complementaria no 131/2009 sobre la publicación de información gubernamental. La investigación se clasifica como descriptivo mediante encuestas, documental con enfoque cuantitativoy cualitativo. Llegamos a la conclusión de que los municipios analizados cumplen con la Ley Complementaria no 131/2009. Sólo el punto que hace referencia a "la disponibilidad de información en tiempo real” no está siendo servida por todos los municipios. El servicio de la Ley № 12.527/2011, el 65\% de los puntos controlados mostraron respuestas positivas, mostrando el compromiso de las autoridades para la divulgación de la información pública. Municipios estudiados no logró grandes avances desde el estudio realizado por el Tribunal de Contas do Estado do Rio Grande do Sul en 2013.

Palabras clave: Transparencia. Las cuentas públicas. Ley № 12.527/2011. Ley Complementaria № 131/2009. 


\section{Nota}

1 Artigo aprovado na XV Convenção de Contabilidade do Rio Grande do Sul, realizado em Bento Gonçalves, em agosto de 2015 .

\section{Referências}

BEUREN, Ilse Maia. Como elaborar trabalhos monográficos em contabilidade: teoria e prática. São Paulo: Atlas, 2003.

BRASIL. (Constituição). Constituição federal: atualizada até janeiro de 2010. Porto Alegre: Editora Verbo Jurídico, 2005. Organizador Nylson Paim de Abreu Filho.

. Lei Complementar no 131, de 27 de maio de 2009. Acrescenta dispositivos à Lei Complementar $n^{\circ} 101$, de 4 de maio de 2000, que estabelece normas de finanças públicas voltadas para a responsabilidade na gestão fiscal e dá outras providências, a fim de determinar a disponibilização, em tempo real, de informações pormenorizadas sobre a execução orçamentária e financeira da União, dos Estados, do Distrito Federal e dos Municípios. Disponível em: <http://www.planalto.gov.br/ccivil_03/leis/LCP/Lcp131.htm>. Acesso em: 21 mar. 2014.

Lei $\mathrm{n}^{\mathrm{o}}$ 12.527, de 18 de novembro de 2011. Regula o acesso a informações previsto no inciso XXXIII do art. $5^{\circ}$, no inciso II do $\S 3^{\circ}$ do art. 37 e no $\S 2^{\circ}$ do art. 216 da Constituição federal; altera a Lei $\mathrm{n}^{\circ}$ 8.112, de 11 de dezembro de 1990; revoga a Lei $\mathrm{n}^{\circ}$ 11.111, de 5 de maio de 2005, e dispositivos da Lei no 8.159, de 8 de janeiro de 1991; e dá outras providências. Disponível em: <http://www. planalto.gov.br/ccivil_03/_ato2011-2014/2011/lei/12527.htm>. Acesso em: 4 set. 2013.

CAVALHEIRO, Jader Branco. A organização do sistema de controle interno municipal. 3. ed. Porto Alegre, Evangraf, 2005.

CASTOLDI, Giovani; SANTOS, Sandra Regina Toledo dos. A transparência na publicação eletrônica das informações municipais disponíveis em suas homepages: uma análise dos municípios pertencentes ao Corede Produção/RS. Revista Teoria e Evidência Econômica, Passo Fundo, a. 19, n. 40, jan./jun. 2013. Disponível em: <http://www.upf.br/cepeac/images/stories/revista_tee_ ano19_n40_2013.pdf>. Acesso em: 28 mar. 2014.

CONSELHO FEDERAL DE CONTABILIDADE. Norma Brasileira de Contabilidade. 2012. Disponível em: <http://portalcfc.org.br/>. Acesso em: 5 set. 2013.

CONTROLADORIA GERAL DA UNIÃO. Guia de implantação de Portal da Transparência. Brasília, 2013a. Disponível em: <http://www.cgu.gov.br/publicacoes/BrasilTransparente/Guia_PortalTransparencia.pdf.>. Acesso em: 5 SET. 2013.

. Manual da Lei de Acesso à Informação para Estados e municípios. Brasília, 2013b. Disponível em: <http://www.cgu.gov.br/publicacoes/BrasilTransparente/Manual_LAI_EstadosMunicipios.pdf>. Acesso em: 28 mar. 2014.

CONSELHO REGIONAL DE DESENVOLVIMENTO DO RIO DA VÁRZEA. Disponível em: $<$ http://corederiodavarzea.com.br/site/>. Acesso em: 25 out. 2013.

DIEHL, Astor Antônio, TATIM, Denise Carvalho. Pesquisa em Ciências Sociais Aplicadas: métodos e técnicas. São Paulo: Pearson Prentice Hall, 2004. 
DI PIETRO, Maria Sylvia Zanella. Direito administrativo. 24. ed. São Paulo: Atlas, 2011.

GIL, Antonio Carlos. Como elaborar projetos de pesquisa. 5. ed. São Paulo: Atlas, 2010.

INSTITUTO DE ESTUDOS SOCIOECONÔMICOS. Transparência Orçamentária nas capitais do Brasil. 2011. Disponível em: <http://www.inesc.org.br/biblioteca/textos/livros/transparencia-orcamentaria-nas-capitais-do-brasil>. Acesso em: 26 abr. 2014.

JUSTEN, Marçal Filho. Curso de direito administrativo. 3. ed. São Paulo: Saraiva, 2008.

KHAIR, Amir Antônio. Gestão fiscal responsável: guia de orientação para as prefeituras. Rio de Janeiro, BNDES, 2001.

KOHAMA, Heilio. Contabilidade pública: teoria e prática. 12. ed. São Paulo: Atlas, 2012.

MARTINS, Douglas da Silva; COELHO, Fabricio Boechat; ALMEIDA, Fernanda Matos de Moura. A importância da implantação do Portal de Transparência Pública na Prefeitura Municipal de Dores do Rio Preto/ES. In: SIMPÓSIO DE EXCELÊNCIA EM GESTÃO E TECNOLOGIA, 9, 2012. Disponível em: <http://www.aedb.br/seget/artigos12/22716555.pdf>. Acesso em 28 mar. 2014.

MELLO, Celso Antônio Bandeira de. Curso de direito administrativo. 28. ed. São Paulo: Malheiros, 2011. MIOLA, Cesar. Lei de Acesso à Informação, seja bem-vinda! Revista do Conselho Regional de Contabilidade do Rio Grande do Sul, Porto Alegre, ed. 14, p. 10-12, mar. 2013.

NEIVA, José Antonio Lisboa. Improbidade administrativa, legislação comentada artigo por artigo: doutrina, legislação e jurisprudência. 2. ed. Niterói: Impetus, 2011.

PISCITELLI, Roberto Bocaccio; TIMBÓ, Maria Zulene Farias; ROSA, Maria Berenice. Contabilidade pública: uma abordagem da administração financeira pública. 6. ed. São Paulo: Atlas, 1999.

PLATT NETO, Orion Augusto et al. Publicidade e transparência das contas públicas: obrigatoriedade e abrangência desses princípios na administração pública brasileira. 2007. Disponível em: <http://web.face.ufmg.br/face/revista/index.php/contabilidadevistaerevista/article/view/320/0>. Acesso em: 5 abr. 2014.

SILVA, Lino Martins da. Contabilidade governamental: um enfoque administrativo da nova contabilidade pública. 9. ed. São Paulo: Atlas, 2011.

SILVA, Moacir Marques; AMORIM, Francisco Antônio de; SILVA, Valmir Leôncio da. Lei de Responsabilidade Fiscal para os municípios: uma abordagem prática. São Paulo: Atlas, 2004.

SLOMSKI, Valmor. Controladoria e governança na gestão pública. 3 reimpr. São Paulo: Atlas, 2009.

SPECK, Bruno Wilhelm (Org.). Caminhos da Transparência. Campinas: Universidade Estadual de Campinas, 2002. Disponível em: <http://www.academia.edu/3810463/bruno_wilhelm_speck_organizador_caminhos_da_transparencia._analise_dos_componentes_de_um_sistema_nacional_de_integridade>. Acesso em: 18 mar. 2014.

TRIBUNAL DE CONTAS DO ESTADO (Rio Grande do Sul). Estudo do Tribunal de Contas avalia transparência dos portais dos municípios. 26 nov. 2013. Disponível em: <http://www1.tce. rs.gov.br/portal/page/portal/tcers/>. Acesso em: 20 jan. 2014.

VIEIRA, Luís Eduardo Píres de Oliveira; FRANÇA, Valdir Lemes da. Transparência e controle da gestão fiscal: a Lei Complementar no 131/09 e sua regulamentação. 2011. Disponível em: <http://www.cpgls.ucg.br/6mostra/artigos/SOCIAIS\%20APLICADAS/LUIS\%20EDUARDO\%20 PIRES\%20DE\%20OLIVEIRA\%20VIEIRA.PDF>. Acesso em 26 abr. 2014.

Teoria e Evidência Econômica - Ano 22, n. 47, p. 331-351, jul./dez. 2016 